\title{
Changes in phosphocreatine concentration of skeletal muscle during high-intensity intermittent exercise in children and adults
}

\author{
J. Kappenstein · A. Ferrauti • B. Runkel • \\ J. Fernandez-Fernandez $\cdot$ K. Müller $\cdot$ \\ J. Zange
}

Received: 1 February 2013/Accepted: 14 August 2013/Published online: 31 August 2013

(C) Springer-Verlag Berlin Heidelberg 2013

\begin{abstract}
Purpose The aim of the present study was to test the hypotheses that a greater oxidative capacity in children results in a lower phosphocreatine (PCr) depletion, a faster $\mathrm{PCr}$ resynthesis and a lower muscle acidification during high-intensity intermittent exercise compared to adults.

Methods Sixteen children ( $9.4 \pm 0.5$ years) and 16 adults (26.1 \pm 0.3 years) completed a protocol consisting of a dynamic plantar flexion (10 bouts of 30-s exercise at $25 \%$ of one repetition maximum separated by 20 -s recovery), followed by $10 \mathrm{~min}$ of passive recovery. Changes of PCr, ATP, inorganic phosphate, and phosphomonoesters were measured by means of ${ }^{31}$ Phosphorous-magnetic resonance spectroscopy during and post-exercise.

Results Average $\mathrm{PCr}$ (percentage of $[\mathrm{PCr}]$ at initial rest $\left.\left(\%[\mathrm{PCr}]_{\mathrm{i}}\right)\right)$ at the end of the exercise (adults $17 \pm$ $12 \%[\mathrm{PCr}]_{\mathrm{i}}$, children $\left.38 \pm 17 \%[\mathrm{PCr}]_{\mathrm{i}}, \quad P<0.01\right)$ and recovery periods (adults $37 \pm 14 \%[\mathrm{PCr}]_{\mathrm{i}}$, children
\end{abstract}

Communicated by Peter Krustrup.

J. Kappenstein $(\bowtie) \cdot$ A. Ferrauti · J. Fernandez-Fernandez Department of Training and Exercise Science, Faculty of Sport Science, Ruhr-University Bochum, Gesundheitscampus Nord Haus Nr. 10, 44780 Bochum, Germany

e-mail: jennifer.kappenstein@rub.de

B. Runkel

Department of Sports Medicine, University of Wuppertal,

Pauluskirchstraße 7, 42285 Wuppertal, Germany

K. Müller · J. Zange

Institute of Aerospace Medicine, German Aerospace Center DLR, Linder Höhe, 51147 Cologne, Germany

J. Zange

Medical Faculty, University of Cologne, 50923 Cologne,

Germany $\left.57 \pm 17 \%[\mathrm{PCr}]_{\mathrm{i}}, \quad P<0.01\right)$ was significantly lower in adults compared to children, induced by a stronger $\mathrm{PCr}$ decrease during the first exercise interval (adults $-73 \pm 10 \%[\mathrm{PCr}]_{\mathrm{i}}$, children $\left.-55 \pm 15 \%[\mathrm{PCr}]_{\mathrm{i}}, P<0.01\right)$. End-exercise $\mathrm{pH}$ was significantly higher in children compared to adults (children $6.90+0.20,-0.14$; adults $6.67+0.23,-0.15, P<0.05)$.

Conclusions From our results we suggest relatively higher rates of oxidative ATP formation in children's muscle for covering the ATP demand of high-intensity intermittent exercise compared to adults, enabling children to begin each exercise interval with significantly higher $\mathrm{PCr}$ concentrations and leading to an overall lower muscle acidification.

Keywords ${ }^{31} \mathrm{P}$-MRS - Intramuscular $\mathrm{pH}$.

Maturation $\cdot$ Muscle metabolism $\cdot$ Recovery

\begin{tabular}{|c|c|}
\hline \multicolumn{2}{|c|}{ Abbreviations } \\
\hline FTI & Force-time integral \\
\hline MR & Magnetic resonance \\
\hline $\mathrm{pH}$ & Intracellular pH \\
\hline $\mathrm{P}_{\mathrm{i}}$ & Inorganic phosphate \\
\hline $\mathrm{PCr}$ & Phosphocreatine \\
\hline PP & Peak power output \\
\hline PME & Phosphomonoesters \\
\hline ROM & Range of motion \\
\hline SD & Standard deviation \\
\hline$\tau$ & Time constant \\
\hline W & Watts \\
\hline WAnT & Wingate anaerobic test \\
\hline $\mathrm{W} / \mathrm{kg} \mathrm{mm}$ & Watts per kilogram muscle mass \\
\hline $1 \mathrm{RM}$ & One repetition maximum \\
\hline${ }^{31} \mathrm{P}-\mathrm{MRS}$ & $\begin{array}{l}{ }^{31} \text { Phosphorous-magnetic resonance } \\
\text { spectroscopy }\end{array}$ \\
\hline$\%\left[\mathrm{PCr}_{\mathrm{i}}\right]$ & Percent of PCr at initial rest \\
\hline
\end{tabular}




\section{Introduction}

It is well known that children differ from adults in their motional behaviour, with a preference for intermittent, high-intensity, and short duration actions (Bailey et al. 1995). These differences are accompanied by developmental-changes (e.g. biological maturation), which influence hormone status and metabolism during childhood (Boisseau and Delamarche 2000). Thus, it is not surprising that during repeated high-intensity exercise bouts (i.e. running or cycling sprints) children also differ from adults, showing a better resistance to fatigue and a faster recovery after exercise (Hebestreit et al. 1993; Ratel et al. 2002a, b; Dotan et al. 2003; Zafeiridis et al. 2005; Paraschos et al. 2007). These age-related differences can be attributed to quantitative and qualitative specific muscle characteristics. Muscle mass and absolute power output increase with maturation. Children's muscles contain a higher percentage of type I fibres which results in a lower glycolytic activity and a higher oxidative capacity compared with adults (Malina 1969; Doré et al. 2000; Van Praagh and Doré 2002). In addition, shorter diffusion distances for respiratory gases and metabolites between the capillaries and the muscle fibres may be responsible for higher rates in oxidative phosphorylation and the subsequent faster $\mathrm{PCr}$ resynthesis, better acid-base regulation, and, for example, a faster lactate removal in children (Falk and Dotan 2006; Ratel et al. 2006).

${ }^{31}$ Phosphorous-magnetic resonance spectroscopy $\left({ }^{31} \mathrm{P}\right.$ MRS) offers a more detailed insight into the metabolic changes occurring in exercising muscles, and seems to be an appropriate technique for studies of children due to its noninvasive nature, positive correlations with muscle biopsy values, and high reliability in different age groups (Cooper and Barstow 1996; Rico-Sanz et al. 1999; Roussel et al. 2000; Larson-Meyer et al. 2001; Bendahan et al. 2002; Barker et al. 2006; Armstrong and Fawkner 2008; Layec et al. 2009).

Although several previous studies using ${ }^{31} \mathrm{P}-\mathrm{MRS}$ provided a better insight into the physiological and metabolic differences between children and adults (Zanconato et al. 1993; Kuno et al. 1995; Taylor et al. 1997; Petersen et al. 1999; Barker et al. 2008a; Ratel et al. 2008; Fleischman et al. 2010; Tonson et al. 2010; Willcocks et al. 2010), research concerning muscle metabolism in children remains incomplete. The potential sex-specificity was considered only sporadically (Barker et al. 2008a; Willcocks et al. 2010). In addition, a detailed quantification of the subject's physical fitness was only reported in moderate but not high-intensity exercises (Zanconato et al. 1993; Barker et al. 2008a, b). In addition, there is a lack of information regarding the use of short high-intensity intermittent exercise in children (only adults have been assessed; Forbes et al. 2008).
In general, there is much controversy in the research comparing children and adults. For example, there is conflicting evidence whether glycolytic activity is lower in children than adults during moderate to high-intensity exercise (Eriksson et al. 1973, 1974; Berg et al. 1986; Zanconato et al. 1993; Kuno et al. 1995; Kaczor et al. 2005; Barker et al. 2008a) or similar between the age groups (Ratel et al. 2008; Tonson et al. 2010; Willcocks et al. 2010). Also, different findings were reported on the mitochondrial oxidative capacity in skeletal muscle estimated by means of post-exercise recovery of $\mathrm{PCr}$, which seems to be directly related to the oxidative metabolism capacity (Meyer 1988; Blei et al. 1993; McCreary et al. 1996; Rossiter et al. 2002). Whether PCr recovery is faster in children than adults (Ratel et al. 2008; Fleischman et al. 2010; Tonson et al. 2010) or shows similar kinetics (Kuno et al. 1995; Barker et al. 2008a) is still disputed. Moreover, the few studies are available in analysing muscle biopsies samples in children compared to adults also lead to different conclusions about the oxidative capacity, with conflicting evidence whether oxidative capacity is greater in children than adults [i.e. with enzymes involved in the citric acid cycle showing higher activity in children and pubescent than in adults (Haralambie 1982; Berg et al. 1986)].

Therefore, the aim of the present study was to analyse the kinetic changes of PCr, ATP, inorganic phosphate $\left(\mathrm{P}_{\mathrm{i}}\right)$, sugar phosphates, and the intracellular $\mathrm{pH}$ by means of ${ }^{31} \mathrm{P}$ MRS in the calf muscle, providing further insight into the mechanisms underlying the faster recovery and the higher fatigue resistance in children compared with adults. We tested the hypotheses that, during high-intensity intermittent plantar flexion exercise, a greater muscle oxidative capacity in children will result in a lower $\mathrm{PCr}$ consumption, a faster PCr resynthesis and therefore, in higher levels of $\mathrm{PCr}$ at the beginning and at the end of each exercise interval, with no sex differences present for both age groups. Also muscle acidification was hypothesised to be lower in children than in adults during the high-intensity intermittent exercise.

\section{Methods}

\section{Participants}

A total of 16 children (eight males and females, age $9.4 \pm 0.5$ years) and 16 adults (eight males and females, age $26.1 \pm 0.3$ years) volunteered to participate in the study (Table 1). The subjects participated in recreational sports (e.g. jogging, tennis and handball in adults or football, swimming and riding in children) for several years (i.e., an average of 2 times per week). Prior to any 
Table 1 Anthropometric data and characteristics of physical fitness

\begin{tabular}{|c|c|c|c|c|c|c|c|}
\hline \multirow[t]{2}{*}{ Variable } & \multirow{2}{*}{$\begin{array}{l}\text { Girls } \\
(n=8)\end{array}$} & \multirow{2}{*}{$\begin{array}{l}\text { Boys } \\
(n=8)\end{array}$} & \multirow{2}{*}{$\begin{array}{l}\text { Women } \\
(n=8)\end{array}$} & \multirow{2}{*}{$\begin{array}{l}\text { Men } \\
(n=8)\end{array}$} & \multicolumn{3}{|c|}{ ANOVA ( $P$ value $)$} \\
\hline & & & & & Age & Sex & Age $\times$ sex \\
\hline Age (years) & $9.4 \pm 0.5$ & $9.4 \pm 0.5$ & $26.3 \pm 1.8$ & $25.9 \pm 3.0$ & $<0.01$ & NS & NS \\
\hline Height $(\mathrm{cm})$ & $139.9 \pm 6.7$ & $138.4 \pm 5.7$ & $170.4 \pm 8.5^{*}$ & $180.1 \pm 3.3^{*}$ & $<0.01$ & $<0.01$ & 0.02 \\
\hline Body mass (kg) & $36.7 \pm 9.6$ & $34.9 \pm 5.7$ & $63.3 \pm 9.6^{*}$ & $74.9 \pm 4.5^{*}$ & $<0.01$ & $<0.01$ & 0.02 \\
\hline Muscle mass (kg) & $16.3 \pm 2.8$ & $16.8 \pm 2.9$ & $32.8 \pm 3.4^{*}$ & $47.4 \pm 3.4^{*}$ & $<0.01$ & $<0.01$ & $<0.01$ \\
\hline Muscle mass $(\% \mathrm{bm})$ & $45.5 \pm 5.4$ & $48.8 \pm 7.4$ & $52.3 \pm 5.1$ & $63.5 \pm 3.5$ & $<0.01$ & $<0.01$ & NS \\
\hline$\dot{V} \mathrm{O}_{2 \text { peak }}(\mathrm{ml} / \mathrm{min} / \mathrm{kg} \mathrm{mm})$ & $97.5 \pm 10.6$ & $105.6 \pm 6.2$ & $94.6 \pm 8.2$ & $87.3 \pm 5.4$ & $<0.01$ & $<0.05$ & NS \\
\hline PP WAnT (W/kg mm) & $19.1 \pm 3.2$ & $18.5 \pm 3.1$ & $25.6 \pm 3.3$ & $20.9 \pm 1.7$ & $<0.01$ & NS & 0.01 \\
\hline MP WAnT (W/kg mm) & $10 \pm 2$ & $10 \pm 1$ & $14 \pm 2$ & $14 \pm 2$ & $<0.01$ & NS & NS \\
\hline
\end{tabular}

Values are mean $\pm \mathrm{SD}$

$B m$ body mass, $\dot{V} O_{2}$ peak highest $\dot{V} \mathrm{O}_{2}$ value attained on an incremental treadmill test until exhaustion, mm muscle mass, PP WAnT Wingate anaerobic test peak power, $M P W A n T$ Wingate anaerobic test mean power

ANOVA, two-way analysis of variance $(* P<0.05)$. NS, no significant differences observed

participation, the experimental procedures and potential risks of the study were fully explained to the participants and their parents. The Ethics committee of the Ruhr-University Bochum approved the project and written informed consent was obtained from the adults and the parents of the children, while the children assented verbally to participate. Pre-experimental medical exams identified that all subjects were healthy and showed no contraindications to exercising.

\section{Experimental protocol}

\section{Study design}

All subjects performed pre-exercise tests in a randomized order to determine their physical fitness. A minimum recovery phase of $24 \mathrm{~h}$ was scheduled between the tests. All subjects were instructed to refrain from intense physical exercise before tests, and to consume their last (carbohydrate rich or fatty) meal at least $2 \mathrm{~h}$ before the scheduled test time. Anthropometric data were collected at the beginning of the first test session. Finally, all subjects performed a standardised rest-exercise-recovery test during which the energy metabolism of the calf muscle was measured by means of ${ }^{31} \mathrm{P}-\mathrm{MRS}$.

\section{Descriptive data}

Anthropometric measurements. Height and body mass were measured using a medical scale (Soehnle Professional 2755, Soehnle Professional GmbH, Backnang, Germany) with subjects wearing socks and light clothes. Muscle mass was estimated by a portable multi-frequency bioelectrical impedance analyser (BIA 101 Anniversary Sport Edition, Akern, Pontassieve, Italy). The analysis was performed after 5 min with the subject lying in a supine position. While the subjects were lying supine, their arms and legs were positioned at an angle of $45^{\circ}$ to the body axis, to avoid the contact of upper and lower extremities with the trunk, which might interfere with the bioimpedance measures. After skin clearing with alcohol wipes, four electrodes were placed on the right side of the body: two on the back of the hand, with one proximal and the other distal to the wrist, and two on the instep of the foot, with one distal and the other proximal to the ankle. A minimum distance of $5 \mathrm{~cm}$ between the two electrodes was calculated.

Physical fitness measurements. An incremental treadmill test (Marathon HS, Heinz Kettler GmbH \& Co KG, EnseParsit, Germany) was used to determine $\dot{V} \mathrm{O}_{2}$ peak. The test began with an initial velocity of $1.6 \mathrm{~m} \cdot \mathrm{s}^{-1}$, increasing $0.4 \mathrm{~m} \cdot \mathrm{s}^{-1}$ every $3 \mathrm{~min}$ until subjective exhaustion, with a constant grade of $1 \%$ (Heck et al. 1985). $\dot{V} \mathrm{O}_{2}$ peak was defined as the highest $\dot{V} \mathrm{O}_{2}$ value measured over 30 s on the test and was normalized to muscle mass.

All subjects performed a Wingate anaerobic test (WAnT) (Bar-Or 1987; Inbar et al. 1996), on a cycle ergometer (Cyclus 2, RBM elektrik automation $\mathrm{GmbH}$, Leipzig, Germany) to calculate mean and peak power output (MP and PP, respectively). Prior to the exercise test, seat height was adjusted to accommodate the subject's stature, such that the knee would be slightly bent at maximal leg extension. A 5-min standardised warm up, consisted of pedalling at a cadence of $80 \mathrm{rpm}$ at a constant power output set at $15 \mathrm{~W}$ (children) and $100 \mathrm{~W}$ (adults) interspersed with three all-out sprints lasting $5 \mathrm{~s}$, was performed (Inbar et al. 1996). After a 5-min rest, subjects were instructed to pedal at full speed with the cycle ergometer unloaded for 5-8 s. At this stage, the full brake force $[F=0.74 \cdot \mathrm{kg} / 0.175$ (children), $F=0.96 \cdot \mathrm{kg} / 0.14$ (adults)] was applied and a 30-s count started (Dotan and 
Bar-Or 1983; Chia et al. 1997). Researchers verbally encouraged the subjects throughout the test. MP and PP, the highest power achieved at any 3-s stage of the test, were normalized to muscle mass.

Estimated one repetition maximum (1RM). To determine the load of the high-intensity dynamic plantar flexion exercise the individual 1RM was estimated in each subject. After a standardised warm-up consisted of 24 repetitions with $10 \mathrm{~kg}$ for children and $20 \mathrm{~kg}$ for adults, subjects were asked to lift the load as often as possible with $50 \%$ of their individual body weight. According to the lifted weight and the number of repetitions the hypothetical 1RM was calculated (Gießing 2003).

Dynamic plantar flexion exercise. During fatiguing exercise and subsequent recovery, depletion and recovery of $\mathrm{PCr}$, ATP, inorganic phosphate $\left(\mathrm{P}_{\mathrm{i}}\right)$, and phosphomonoesters (PME, sugar phosphates), were measured in the right calf muscle by ${ }^{31} \mathrm{P}-\mathrm{MRS}$, following the methods of Zange et al. (2008). Subjects were lying on a treatment table, in a supine position, with their legs in the $40 \mathrm{~cm}$ diameter bore of the magnetic resonance (MR) magnet. The right calf was placed on a calf holder with integrated ${ }^{1} \mathrm{H} /{ }^{31} \mathrm{P}-\mathrm{MR}$ surface coil, with the leg slightly flexed (approximately $10^{\circ}$ ). The right foot was fixed with straps on a pedal linked to a load via a block and tackle construction. The footplate of the pedal could be turned between $70^{\circ}$ and $40^{\circ}$ relative to the horizontal position. The lift of the load was optically measured using a striated tape and a photoelectric relay, in order to calculate the forcetime integral (FTI) and FTI per $\mathrm{kg}$ of body mass (FTI/ $\mathrm{kg} \mathrm{bm})$ as well as the range of motion (ROM) per lift (Zange et al. 2008).

After 1 min lying at rest, serving as baseline reference, the dynamic interval exercise began, consisting of ten bouts of 30-s exercise interspersed 20-s rest periods. After the 10th exercise bout, subjects rested for $10 \mathrm{~min}$. Subjects were asked to lift the load ( $25 \%$ of their individual estimated 1RM) 24 times per exercise bout, following an audible signal. Subjects were verbally encouraged throughout the exercise to complete the whole ROM during each plantar flexion.

${ }^{31} P$-MRS and energy metabolism. The MR spectra of the calf were obtained in a 4.7 Tesla $40 \mathrm{~cm}$ horizontal bore spectrometer using a $5-\mathrm{cm}$ diameter ${ }^{1} \mathrm{H} /{ }^{31} \mathrm{P}$ surface coil (Bruker-Biospec 47/40, Bruker-Medical, Ettlingen, Germany). This coil was placed below the belly of the right calf. The resonance frequencies were $200 \mathrm{MHz}$ for ${ }^{1} \mathrm{H}$ and $81 \mathrm{MHz}$ for ${ }^{31} \mathrm{P}$, respectively. ${ }^{1} \mathrm{H}$ spectra were used to optimise magnetic field homogeneity (shimming). For the water signal a line half width lower than $48 \mathrm{~Hz}$ was accepted. In most examinations, a value better than $40 \mathrm{~Hz}$ was reached. A pulse length of $100 \mu$ s was used for ${ }^{31} \mathrm{P}$ MRS. The flip angle was $60^{\circ}$ at the centre of the coil. For each spectrum, eight free induction decays (FIDs) were acquired in $10 \mathrm{~s}$. The vector size was 2,048 complex data points. The smaller surface coil size and the lower flip angle degree were chosen to insure that similar parts of the two working muscles [soleus (80-90\% type I) and gastrocnemius (50\% type I, $50 \%$ type II)] are measured in both age groups. In addition, a minimisation of the participation of the soleus by lower ingression energy was pursued (Barker and Armstrong 2010).

Spectra were evaluated for $\mathrm{PCr}, \mathrm{P}_{\mathrm{i}}$, beta phosphate in ATP, and for PME [sugar phosphates including predominantly glucose-6-phosphate (Rothman et al. 1992)].

Metabolic concentrations were generally given in percent of $[\mathrm{PCr}]$ at initial rest $\left(\%[\mathrm{PCr}]_{\mathrm{i}}\right)$. The areas under each peak relative to the $\mathrm{PCr}$ peak were corrected for partial spin saturation comparing the peak ratios from spectra with fully relaxed spins (10 s pulse repetition time) with spectra recorded at $1.25 \mathrm{~s}$ pulse repletion time. The following factors were determined and used to correct the $\%[\mathrm{PCr}]_{\mathrm{i}}$ values: PME 1.24, $P_{i} 1.03$ and ATP 0.82. We assumed that these factors were constant throughout the experiment. Finally all peak areas were corrected for losses in the RFsignal causes by the motion of the calf during exercise. The correction factor was calculated from the ratio of sum of all evaluated signal integrals of the current spectrum and the corresponding sum of the first spectrum recorded at rest.

The time course of the final $\mathrm{PCr}$ recovery following the 10th set of exercise was fitted with the non-linear regression function for fitting an exponential rise to maximum with three parameters provided by the software Sigmaplot 11 (Systat Software GmbH, Erkrath, Germany). Correlation coefficients were better than 0.90 and in all cases correlations were highly significant $(P<0.01)$. The time constant ( $\tau$ in s) was used as an indicator for the capacity of oxidative ATP formation.

$\operatorname{PCr}(\mathrm{t})=\operatorname{PCr}(t=0)+a\left(1-\mathrm{e}^{-t / \tau}\right)$

The intracellular $\mathrm{pH}(\mathrm{pH})$ was determined by the chemical shift of the phosphate peak ( $\delta$ in $\mathrm{ppm})$ relative to PCr (Taylor et al. 1983; Arnold et al. 1984). The resonance frequency of the $\mathrm{PCr}$ signal was defined as $0 \mathrm{ppm}$.

$\mathrm{pH}=6.75+\log ((\delta-3.27) /(5.69-\delta))$

Statistical analysis

Data were expressed as mean values \pm standard deviations (SD). The logarithmic $\mathrm{pH}$-values were averaged as $\mathrm{H}^{+}$ concentrations $\pm \mathrm{SD}$ which resulted in asymmetrical SDs in mean $\mathrm{pH}$-values. The subject's anthropometric data and characteristics of physical fitness as well as the variables describing the average mechanical performance during plantar flexion exercise, the initial and final metabolite 
levels as well as the post-exercise recovery time constant $\tau$ determined by ${ }^{31} \mathrm{P}$-MRS were compared using a two-way analysis of variance with the main factors age (adults vs. children) and sex (males vs. females). A multifactor repeated measure analysis of variance was used to determine significant effects for age, sex and time for the metabolite levels at the end of each set of the ten exercise intervals and after each 20 -s recovery period, respectively. For all statistical analysis a significance level of $P<0.05$ was used.

\section{Results}

The anthropometric data and physical fitness characteristics of each group are shown in Table 1. Results showed significant main effects $(P \leq 0.01)$ for age in all the variables analysed. Significant main effects for sex $(P<0.01)$ and age $\times$ sex interactions $(P<0.05)$ were calculated partially (Table 1$)$. Significant main effects $(P<0.05)$ for sex were only found in adults.

Resting muscle metabolic values did not differ between the age and sex groups. Changes in $\mathrm{PCr}$ as well as $\mathrm{P}_{\mathrm{i}}$, ATP, $\mathrm{PME}$ and $\mathrm{pH}$ in the calf muscle of children and adults during the high-intensity exercise and post-exercise recovery are illustrated in Figs. 1, 2, 3, 4, and 5 and also reported in Table 2.

The time course of $\mathrm{PCr}$ is shown in Fig. 1. During the plantar flexion exercise, average $\mathrm{PCr}$ at the end of the exercise (girls $38 \pm 22 \%[\mathrm{PCr}]_{\mathrm{i}}$, boys $37 \pm 17 \%[\mathrm{PCr}]_{\mathrm{i}}$, women $17 \pm 12 \%[\mathrm{PCr}]_{\mathrm{i}}$, men $\left.18 \pm 16 \%[\mathrm{PCr}]_{\mathrm{i}}\right)$ and recovery (girls $54 \pm 21 \%[\mathrm{PCr}]_{\mathrm{i}}$, boys $60 \pm 18 \%[\mathrm{PCr}]_{\mathrm{i}}$,

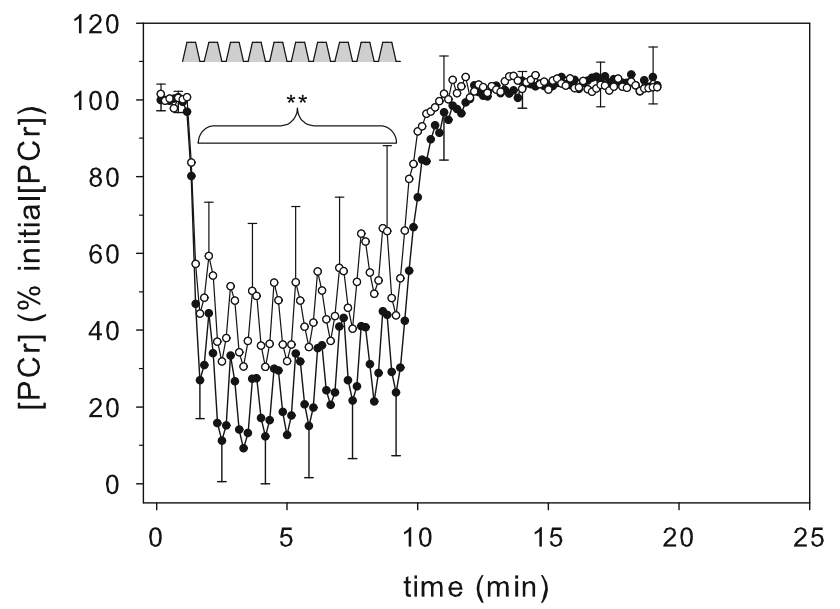

Fig. 1 Changes in phosphocreatine (PCr, \% initial, mean \pm SD) in the calf muscles of adults (filled circles, $n=16$ ) and children (open circles, $n=16$ ) during ten sets of 30-s high-intensity dynamic plantar flexion followed by 20 -s recovery in between sets and 10-min postexercise recovery. $* *$ During exercise $P<0.01$ for all: end-contraction (age, time), end-recovery (age, time; ANOVA), no significant differences were found for sex and the interactions women $36 \pm 18 \%[\mathrm{PCr}]_{\mathrm{i}}$, men $38 \pm 18 \%[\mathrm{PCr}]_{\mathrm{i}}$ ) periods was significantly lower in adults compared to children $(P<0.01)$, with no sex or interaction effects. $\mathrm{PCr}$ decrease during the first exercise bout $\left(\mathrm{PCr}_{\Delta \text { int } 1}\right)$ was significantly lower in children (girls $-50 \pm 12 \%[\mathrm{PCr}]_{\mathrm{i}}$, boys $-60 \pm$ $17 \%[\mathrm{PCr}]_{\mathrm{i}}$ ) compared to adults (women $-77 \pm$ $12 \%[\mathrm{PCr}]_{\mathrm{i}}$, men $\left.-69 \pm 7 \%[\mathrm{PCr}]_{\mathrm{i}}\right)(P<0.01)$, with no difference found for the subsequent exercise intervals. There was no main effect for sex, but an interaction between age and sex was identified for the first exercise interval $(P<0.05)$ (Table 2).

The level of $\mathrm{P}_{\mathrm{i}}$ nearly mirrored the time course of $\mathrm{PCr}$ (Fig. 2; Table 2). Accordingly, average $P_{i}$ was significantly

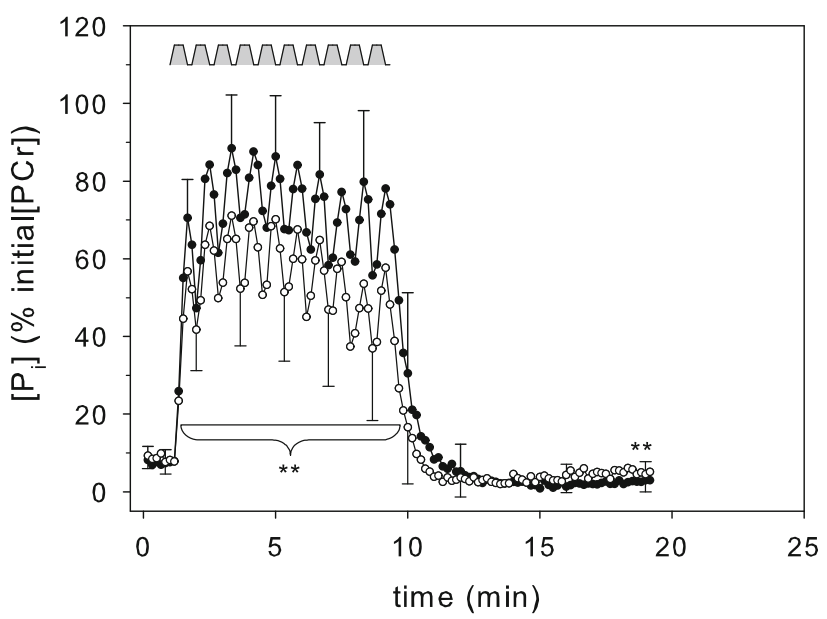

Fig. 2 Changes in inorganic phosphate $\left(\mathrm{P}_{\mathrm{i}}, \%\right.$ initial $[\mathrm{PCr}]$, mean $\pm \mathrm{SD}$ ) in the calf muscles of adults (filled circles, $n=16$ ) and children (open circles, $n=16$ ) during ten sets of 30-s highintensity dynamic plantar flexion followed by 20 -s recovery in between sets and $10 \mathrm{~min}$ post-exercise recovery. $* * P<0.01$ during exercise for all: end-contraction (age, time), end-recovery (age, time, age $\times$ time) as well as last $\min$ of post-exercise recovery (age; ANOVA), no significant differences were found for sex and further interactions

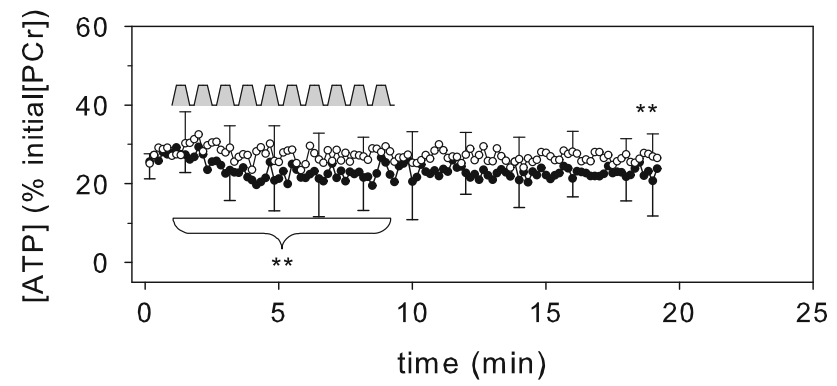

Fig. 3 Changes in ATP (\% initial $[\mathrm{PCr}]$, mean $\pm \mathrm{SD}$ ) in the calf muscles of adults (filled circles, $n=16$ ) and children (open circles, $n=16$ ) during ten sets of 30-s high-intensity dynamic plantar flexion followed by 20 -s recovery in between sets and 10 min post-exercise recovery. ${ }^{*}$ During exercise: end-contraction (age $P=0.02$, time $P<0.01$ ), end-recovery (age $P<0.01$, time $P=0.03$ ) as well as last min of post-exercise recovery (age $P<0.01$; ANOVA), no significant differences were found for sex and interactions 


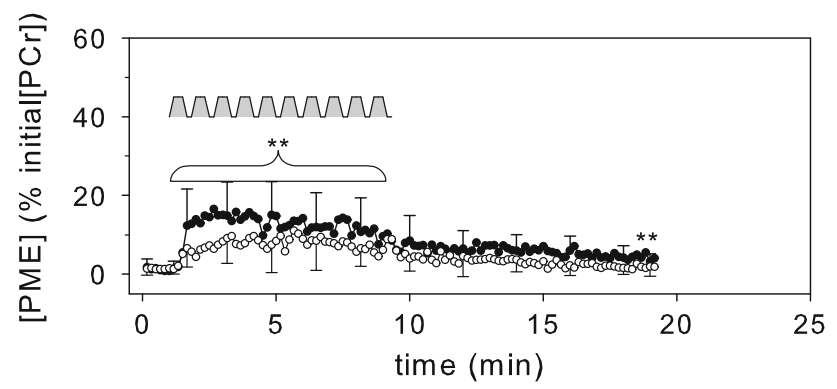

Fig. 4 Changes in phosphomonoesters (PME, predominantly glucose-6-phosphate, \% initial [PCr], mean $\pm \mathrm{SD}$ ) in the calf muscles of adults (filled circles, $n=16$ ) and children (open circles, $n=16$ ) during ten sets of 30 -s high-intensity dynamic plantar flexion followed by 20 -s recovery in between sets and $10 \mathrm{~min}$ post-exercise recovery. $* * P<0.01$ during exercise for all: end-contraction (age, time), end-recovery (age, time, age $\times$ time) as well as last min of post-exercise recovery (age; ANOVA), no significant differences were found for sex and further interactions

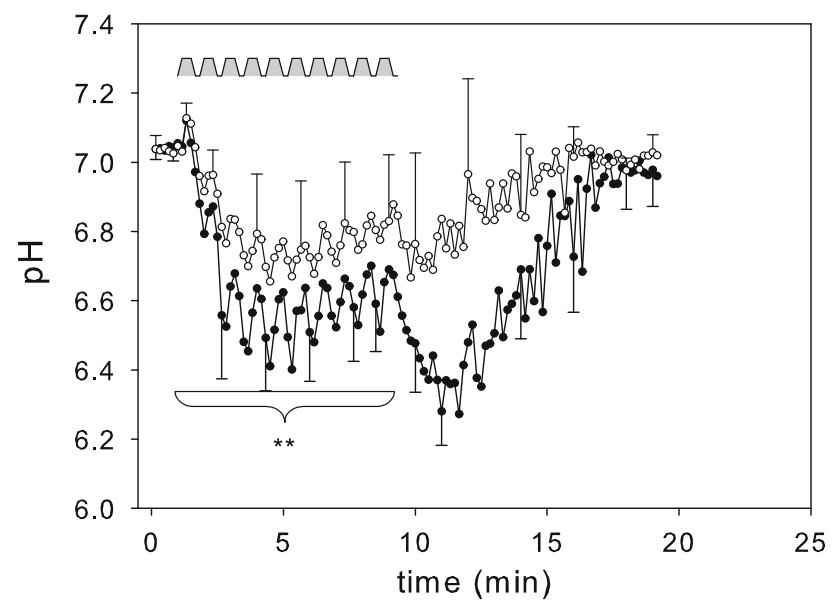

Fig. 5 Changes in $\mathrm{pH}$ (mean $\pm \mathrm{SD}$ ) in the calf muscles of adults (filled circles, $n=16$ ) and children (open circles, $n=16$ ) during ten sets of 30-s high-intensity dynamic plantar flexion followed by 20 -s recovery in between sets and $10 \mathrm{~min}$ post-exercise recovery. $* * P<0.01$ during exercise for all: end-contraction (age, time), end-recovery (age, time, age $\times$ time; ANOVA), no significant differences were found for sex and further interactions

lower in children than in adults at the end of each exercise (girls $65 \pm 22 \%[\mathrm{PCr}]_{\mathrm{i}}$, boys $62 \pm 14 \%[\mathrm{PCr}]_{\mathrm{i}}$, women $82 \pm 14 \%[\mathrm{PCr}]_{\mathrm{i}}$, men $\left.81 \pm 17 \%[\mathrm{PCr}]_{\mathrm{i}}\right)$ and recovery period (girls $48 \pm 20 \%[\mathrm{PCr}]_{\mathrm{i}}$, boys $41 \pm 15 \%[\mathrm{PCr}]_{\mathrm{i}}$, women $64 \pm 20 \%[\mathrm{PCr}]_{\mathrm{i}}$, men $63 \pm 20 \%[\mathrm{PCr}]_{\mathrm{i}}$ ) during plantar flexion exercise $(P<0.01)$, with no sex or interaction effects.

ATP levels were significantly lower in adults (women $22 \pm 9 \%[\mathrm{PCr}]_{\mathrm{i}}$, men $\left.22 \pm 8 \%[\mathrm{PCr}]_{\mathrm{i}}\right)$ compared to children (girls $26 \pm 7 \%[\mathrm{PCr}]_{\mathrm{i}}$, boys $28 \pm 7 \%[\mathrm{PCr}]_{\mathrm{i}}$ ) during the plantar flexion exercise $(P<0.01)$, with no sex or interaction effects (Table 2). At the end of the exercise ATP levels in adults were significantly lower than at rest $\left(22 \pm 6 \%[\mathrm{PCr}]_{\mathrm{i}}\right.$ vs. $\left.27 \pm 4 \%[\mathrm{PCr}]_{\mathrm{i}}, P<0.01\right)$, while in children ATP levels did not significantly decrease during exercise (Fig. 3).

For PME no differences were found for the age and sex groups during exercise (Fig. 4). End-exercise pH was significantly higher in children compared to adults (girls $6.81+0.16,-0.12$; boys $7.00+0.14,-0.11$; women $6.63+0.26,-0.16$; men $6.71+0.21,-0.14, P<0.05)$ (Fig. 5).

During the $10 \mathrm{~min}$ recovery after the high-intensity dynamic plantar flexion exercise, $\mathrm{PCr}$ increased in a exponential manner to a value close to rest in both age and sex groups (girls $103 \pm 2 \%[\mathrm{PCr}]_{\mathrm{i}}$, boys $103 \pm 2 \%[\mathrm{PCr}]_{\mathrm{i}}$, women $104 \pm 5 \%[\mathrm{PCr}]_{i}$, men $104 \pm 3 \%[\mathrm{PCr}]_{i}$; Fig. 1). In children the time constants of $\mathrm{PCr}$ increase $(\tau)$ were smaller than in adults (girls $45 \pm 33 \mathrm{~s}$, boys $24 \pm 8 \mathrm{~s}$, women $44 \pm 18 \mathrm{~s}$, men $55 \pm 27 \mathrm{~s}$ ) which, however, only approached statistical significance $(P=0.09)$ because of a large variability of $\tau$ values in both groups. No sex effects or interactions were identified for $\tau$.

Table 3 shows the mechanical performance data obtained during the ten sets of exercise. The lifted load was significantly lower in children (girls $19.4 \pm 4.0 \mathrm{~kg}$, boys $19.8 \pm 3.6 \mathrm{~kg}$ ) compared to adults (women $37.2 \pm 3.9 \mathrm{~kg}$, men $45.0 \pm 2.7 \mathrm{~kg})(P<0.01)$, resulting in significantly lower absolute force-time integrals per lift (girls $140 \pm 42$ Ns, boys $93 \pm 33$ Ns, women $233 \pm 79$ Ns, men $228 \pm 63$ Ns) $(P<0.01)$. After correction for body mass all significant age specific differences disappeared. The normalised force-time integrals per lift and the range of motion did not differ between the age groups. No sex effects or age $\times$ sex interactions were identified for the mechanical performance data.

\section{Discussion}

The aim of the present study was to analyse the kinetic changes of $\mathrm{PCr}$, ATP, inorganic phosphate $\left(\mathrm{P}_{\mathrm{i}}\right)$, sugar phosphates, and the intracellular $\mathrm{pH}$ by means of ${ }^{31} \mathrm{P}$-MRS in the calf muscles during high-intensity intermittent plantar flexion exercise, in children compared with adults. It was hypothesised that the greater muscle oxidative capacity in children will result in a lower $\mathrm{PCr}$ consumption, a faster PCr resynthesis and therefore, in higher levels of $\mathrm{PCr}$ at the beginning and at the end of each exercise interval, with no sex differences in both age groups. Also muscle acidification was hypothesised to be lower in children than in adults during the high-intensity intermittent exercise. These hypotheses were only partially supported by the present results, showing that $\mathrm{PCr}$ breakdown was significantly greater in adults compared to children only during the first exercise interval. The $\mathrm{PCr}$ breakdown and recovery was similar in children and adults in the 
Table 2 Exercise induced changes in PCr, $\mathrm{P}_{\mathrm{i}}$ and ATP

\begin{tabular}{|c|c|c|c|c|c|c|}
\hline Variable & $\mathrm{x} ;^{-}$ & $\begin{array}{l}\text { Girls } \\
(n=8)\end{array}$ & $\begin{array}{l}\text { Boys } \\
(n=8)\end{array}$ & $\begin{array}{l}\text { Women } \\
(n=8)\end{array}$ & $\begin{array}{l}\text { Men } \\
(n=8)\end{array}$ & $\begin{array}{l}\text { ANOVA age } \\
(P \text { value })\end{array}$ \\
\hline \multirow[t]{4}{*}{$\mathrm{PCr}$} & int1 & $50 \pm 12$ & $40 \pm 17$ & $23 \pm 16$ & $31 \pm 7$ & $<0.01$ (f) \\
\hline & int 2 to int 10 & $37 \pm 23$ & $37 \pm 17$ & $16 \pm 12$ & $17 \pm 15$ & $<0.01(\mathrm{rm})$ \\
\hline & $\Delta$ int 1 & $-50 \pm 12$ & $-60 \pm 17$ & $-77 \pm 12$ & $-69 \pm 7$ & $<0.01(\mathrm{f})^{\mathrm{a}}$ \\
\hline & $\Delta$ int 2 to int 10 & $-19 \pm 13$ & $-20 \pm 9$ & $-18 \pm 13$ & $-22 \pm 11$ & NS (rm) \\
\hline \multirow[t]{4}{*}{$P_{i}$} & int1 & $74 \pm 9$ & $67 \pm 11$ & $54 \pm 11$ & $59 \pm 14$ & $<0.01$ (f) \\
\hline & int 2 to int 10 & $83 \pm 15$ & $83 \pm 17$ & $66 \pm 22$ & $63 \pm 15$ & $<0.01(\mathrm{rm})$ \\
\hline & $\Delta$ int 1 & $45 \pm 11$ & $51 \pm 14$ & $66 \pm 8$ & $60 \pm 11$ & $<0.01$ (f) \\
\hline & $\Delta \mathrm{int} 2$ to int 10 & $17 \pm 11$ & $21 \pm 10$ & $19 \pm 16$ & $22 \pm 12$ & NS (rm) \\
\hline ATP & int 1 to int 10 & $26 \pm 7$ & $28 \pm 7$ & $22 \pm 9$ & $22 \pm 8$ & $<0.01(\mathrm{rm})$ \\
\hline
\end{tabular}

Values are mean $\pm \mathrm{SD}$

Int mean levels $\left[\% \mathrm{PCr}_{\mathrm{i}}\right]$ at the end of exercise interval, $\Delta i n t$ mean changes during exercise intervals from initial rest (int 1$)$ or the end of the previous recovery interval (int2 to int10)

ANOVA, analysis of variance (f, factorial; rm, repeated measure; $P<0.05$ ). NS, no significant differences observed

a Age $\times$ sex: $P<0.05$. No further significant differences were found for sex and sex $\times$ age

Table 3 Average mechanical performance during the ten sets of exercise

\begin{tabular}{lccccc}
\hline Variable & $\begin{array}{l}\text { Girls } \\
(n=8)\end{array}$ & $\begin{array}{l}\text { Boys } \\
(n=5)\end{array}$ & $\begin{array}{l}\text { Women } \\
(n=8)\end{array}$ & $\begin{array}{l}\text { Men } \\
(n=8)\end{array}$ & $\begin{array}{l}\text { ANOVA age } \\
(P \text { value })\end{array}$ \\
\hline Load $(\mathrm{kg})$ & $19.4 \pm 4.0$ & $19.8 \pm 3.6$ & $37.2 \pm 3.9$ & $45.0 \pm 2.7$ & $<0.01$ \\
Load $(\%$ bm) & $53.7 \pm 7.0$ & $56.7 \pm 4.4$ & $59.3 \pm 5.3$ & $60.2 \pm 3.2$ & $228 \pm 63$ \\
FTI $_{1}(\mathrm{Ns})$ & $140 \pm 42$ & $93 \pm 33$ & $233 \pm 79$ & $231 \pm 19$ & $<.02$ \\
FTI $_{\varnothing}(\mathrm{Ns})$ & $119 \pm 18$ & $81 \pm 24$ & $206 \pm 19$ & $2.5 \pm 0.6$ & $2.2 \pm 0.6$ \\
FTI $_{1}(\mathrm{Ns} / \mathrm{kg} \mathrm{bm})$ & $3.8 \pm 1.4$ & $3.0 \pm 0.9$ & $3.4 \pm 1.3$ & $28 \pm 12$ & $\mathrm{NS}$ \\
FTI $_{\varnothing}(\mathrm{Ns} / \mathrm{kg} \mathrm{bm})$ & $3.4 \pm 1.3$ & $3.1 \pm 0.7$ & $33 \pm 12$ & $24 \pm 3$ & $\mathrm{NS}$ \\
ROM $_{1}(\mathrm{~mm})$ & $30 \pm 14$ & $28 \pm 6$ & $28 \pm 2$ & $22 \pm 5$ & $\mathrm{NS}$ \\
ROM $_{\varnothing}(\mathrm{mm})$ & $23 \pm 4$ & &
\end{tabular}

Values are mean $\pm \mathrm{SD}$

$B m$ body mass, $F T I$ force-time integral per lift, $F T I_{1}$ during the first exercise interval, $F T I_{\emptyset}$ average during all exercise intervals, $N s$ newton second, $R O M$ range of motion, $\mathrm{mm}$ millimeter

ANOVA, two-way analysis of variance $(P<0.05)$. NS, no significant differences observed. No significant differences were found for sex and age $\times \operatorname{sex}$

subsequent exercise, such that the overall $\mathrm{PCr}$ concentration oscillated between exercise and recovery intervals at a higher level in children than in adults (Fig. 1; Table 2). Together with a significantly lower muscle acidification in children during exercise, results point to higher rates in oxidative phosphorylation and lower rates of anaerobic ATP formation in children's muscle than in adult's, during high-intensity intermittent exercise. Moreover, and concerning the metabolic responses during the exercise protocol we did not find differences between sex groups (i.e., boys vs. girls, women vs. men).

In order to have a valid metabolic comparison between children and adults there were important methodological prerequisites, which were that the mechanical load and the initial muscle metabolic values were comparable for both age and sex groups. The loads used during the highintensity intermittent protocol normalised to $25 \% 1 \mathrm{RM}$ also resulted in almost equal loads per body mass, and relative force-time integrals as well as the range of motion for the initial exercise interval and for the mean of the subsequent intervals, were similar in both age groups (Table 3). Moreover, the initial ratios of $\mathrm{PCr} / \mathrm{ATP}, \mathrm{PCr} / \mathrm{Pi}$, and $\mathrm{PCr} / \mathrm{PME}$, as well as the initial $\mathrm{pH}$ formed a comparable baseline for age and sex groups, which was in agreement with several previous studies using muscle biopsies or ${ }^{31} \mathrm{P}$-MRS (i.e., in the calf or finger flexor muscles) (Eriksson 1980; Taylor et al. 1997; Barker et al. 2008a; Ratel et al. 2008; Tonson et al. 2010).

A general examination of our results showed that, during the high-intensity intermittent plantar flexion exercise, the 
kinetics of $\mathrm{PCr}$ concentrations showed a normal pattern (i.e., depletion and repletion), which was accompanied by a stoichiometric increase and decrease of $P_{i}$ levels (Figs. 1, 2). The time course of $\mathrm{pH}$ also followed the $\mathrm{PCr}$ concentrations pattern. In addition average $\mathrm{pH}$ decreased, which was likely caused by the formations of lactic acid and $\mathrm{CO}_{2}$ which both resulted in an accumulation of protons (Kemp et al. 1993) (Fig. 5). The length of the rest intervals was adequate to generate an incomplete but significant $\mathrm{PCr}$ recovery as a precondition to maintain constant ATP levels at least in children (Fig. 3). Overall, these results are in agreement with previous research (Kemp and Radda 1994; Kemp et al. 2005; Barker and Armstrong 2010). However, in adults, ATP levels were decreased during the exercise protocol and were not recovered until the end of the test. This moderate persisting decrease in adenine nucleotides may indicate that in adult muscle $\mathrm{PCr}$ reached so low levels that ADP activated the myokinase forming AMP and ATP from 2 ADP. Typically AMP leaves the adenine nucleotide pool by deamination and the purine nucleotide cycle (Lowenstein 1990).

Results from the present study showed important differences comparing children and adults. PCr levels observed throughout the exercise remained significantly higher in children than in adults, both at the end of each exercise bout $\left(38 \pm 17 \%[\mathrm{PCr}]_{\mathrm{i}}\right.$ vs. $17 \pm 12 \%[\mathrm{PCr}]_{\mathrm{i}}$, $P<0.01)$ and after each recovery period $\left(57 \pm 17 \%[\mathrm{PCr}]_{\mathrm{i}}\right.$ vs. $37 \pm 14 \%[\mathrm{PCr}]_{\mathrm{i}}, P<0.01$ ) (Table 2; Fig. 1), together with a significantly lower muscle acidification, probably due to the creatine-kinase reaction (Conley et al. 2001). This might be related to the lower $\mathrm{PCr}$ consumption observed during the first exercise interval in children compared to adults $\left(55 \pm 15 \%[\mathrm{PCr}]_{\mathrm{i}}\right.$ vs. $73 \pm 10 \%[\mathrm{PCr}]_{\mathrm{i}}$, $P<0.01)$. In adults the recovery from significantly lower end-exercise $\mathrm{PCr}$ levels caused a stronger additional decrease in $\mathrm{pH}$ at the onset of post-exercise recovery compared to children.

During the first exercise interval the lower $\mathrm{PCr}$ consumption in children might be explained by the oxidative phosphorylation, which in children covers a large portion of the ATP demands earlier than in adults (Cooper and Barstow 1996; Williams et al. 2001; Fawkner et al. 2002; Fawkner and Armstrong 2004). As the relative force-time integral per lift and the range of motion during the first exercise interval were similar in both age groups (Table 3), this can be excluded as influencing factor. Thus, it seems that children possess a faster metabolic adaptation from rest to high-intensity exercise. In this regard, there are only a few studies measuring $\mathrm{PCr}$ kinetics at the onset of exercise in children, with results showing similar $\mathrm{PCr}$ kinetics in children and adults during the transition from rest to continuous exercise (Barker et al. 2008a; Tonson et al. 2010). However, in contrast to the methods used in the present study, previous research used less intensive work-rate protocols, which makes it difficult to establish comparisons. Information about $\dot{V} \mathrm{O}_{2}$ kinetics can provide further insight into the $\mathrm{PCr}$ kinetics, assuming that it is directly linked to pulmonary $\dot{V} \mathrm{O}_{2}$ kinetics during moderate and heavy intensity exercise (Barstow et al. 1994; Rossiter et al. 2002; Barker et al. 2008b). It was shown that children show a significant faster on-transient $\dot{V} \mathrm{O}_{2}$ kinetic in moderate and intense exercise compared to adults (Cooper et al. 1985; Williams et al. 2001; Fawkner et al. 2002; Fawkner and Armstrong 2004), achieving a greater percentage of their $\dot{V} \mathrm{O}_{2}$ max during the first $30 \mathrm{~s}$ of intensive exercise (Armon et al. 1991). This would support the lower PCr consumption during the first exercise bout in children in the present study. Moreover the higher accumulation of PME at the onset of the interval exercise in adults may suggest that they rely more on the anaerobic metabolism (Rothman et al. 1992; Crowther et al. 2002). In summary, the changes in PCr and PME showed that in adult's muscles, ATP production during exercise relied more on anaerobic sources like PCr, whereas children show a faster metabolic adaptation from rest to exercise due to a stronger participation of the oxidative energy production.

Although we do not have enough measurements on the oxidative capacity to support this idea, the faster $\dot{V} \mathrm{O}_{2}$ kinetic at the onset of exercise observed in children might be explained by several factors. Children possess a higher capillary density and a better intramuscular perfusion which is related to an enhanced muscle blood flow (Zanconato et al. 1993; Falk and Dotan 2006; Tonson et al. 2010). Comparing children and adults at similar intense exercise, convective or diffusive oxygen supply may contribute to the greater proportion of oxidative energy provision during contraction and recovery in children than in adults. A previous study conducted with adults showed that an improved blood and oxygen supply by means of lower body negative pressure significantly enhances oxidative ATP formation and fatigue resistance during intensive interval exercise compared to control conditions (Zange et al. 2008). Since adult muscle becomes ischaemic under high load contraction, the initial $\mathrm{PCr}$ decrease was the same with and without lower body negative pressure. The improved oxidative metabolism by lower body negative pressure during interval exercise in adults becomes visible in the recovery phases from contraction. However, the comparison of children and adults in the present study shows different $\mathrm{PCr}$ decreases at the first exercise interval, which hints that children may better maintain muscle perfusion during the initial interval bout than adults, under comparable loads normalised to 1RM. In addition to differences in muscle perfusion, differences in mitochondrial capacity and fibre type recruitment may contribute to the 
different metabolic reactions observed for children and adults in this study (Bell et al. 1980; van Ekeren et al. 1991; Lexell et al. 1992; Evans and Lexell 1995; Malina et al. 2004; Dotan et al. 2012).

During the second and subsequent exercise intervals no further significant differences concerning the $\mathrm{PCr}$ time course were found between age groups, although children began the second exercise bout with significant higher $\mathrm{PCr}$ levels $\left(60 \pm 14 \%[\mathrm{PCr}]_{\mathrm{i}}\right.$ vs. $\left.44 \pm 9 \%[\mathrm{PCr}]_{\mathrm{i}} ; \quad P<0.01\right)$ (Fig. 1). While in this phase PCr equally contributed to the ATP formation in both age groups, a stronger participation of the anaerobic glycolysis in adults is reflected by the significantly stronger $\mathrm{pH}$ drop during exercise (Fig. 5). The significantly higher $\mathrm{PCr}$ and $\mathrm{pH}$ values in children compared to adults during repetitive bouts of high-intensity exercise are in agreement with previous research (Zanconato et al. 1993; Ratel et al. 2008). The large differences in the $\mathrm{pH}$ drop during post-exercise recovery were caused by the magnitudes of resynthesized $\mathrm{PCr}$ and the buffer capacity properties of PCr (Robergs et al. 2004).

During post-exercise recovery, the time constant $\tau$ approached statistical significance $(P=0.099)$, suggesting a faster PCr recovery in children than in adults. A major part of previous research analysing the PCr kinetics during post-exercise recovery showed a faster $\mathrm{PCr}$ recovery in children compared to adults after submaximal and maximal exercises (Taylor et al. 1997; Ratel et al. 2008; Fleischman et al. 2010), whereas only one study found no differences between pubertal children and adults after a moderateintense exercise (Barker et al. 2008a). Unfortunately, $\tau$ values in our study showed a rather large variability in both age groups. The difference in $\tau$-values became significant when the smallest and highest values were eliminated before statistical analyses in both groups. Nevertheless, the lower $\tau$-value in children may not necessarily indicate a higher mitochondrial capacity in children, because of the different starting levels of PCr recovery in children and adults. It was previously shown that a slower $\mathrm{PCr}$ resynthesis in adults might be related to lower end-exercise $\mathrm{PCr}$ levels and a higher acidosis, due to a positive correlation in $\mathrm{PCr}$ recovery with end- exercise $\mathrm{pH}$ and maximum $\mathrm{pH}$ drop during recovery (Bendahan et al. 1990; Kemp and Radda 1994). We can speculate that, this correlation could also be explained by a temporary oxygen deficit during recovery due to the very low end-exercise PCr levels found in adults, although the previous mentioned research theoretically exclude this fact. Our assumption can be supported by the fact that lower PCr levels at the end of the contraction intervals result in higher levels of $\mathrm{Pi}$ and ADP, which both would result in higher rates of oxidative phosphorylation by the mitochondria in case oxygen would not become a rate limiting substrate (Kemp and Radda 1994). Despite the post-exercise reactive hyperaemia, oxygen supply of mitochondria may not meet the theoretically high oxygen demand given by the activation, through $\mathrm{P}_{\mathrm{i}}$ and ADP at very low PCr levels. The visibility of deoxymyoglobin for about $45 \mathrm{~s}$ after exhaustive exercise (Tran et al. 1999) indicates a rather slow reoxygenation of the sarcoplasma. Also the effects of lower body negative pressure on $\mathrm{PCr}$ recovery after intensive exercise, previously mentioned (Zange et al. 2008) only makes sense if oxygen was rate limiting for oxidative phosphorylation during recovery at least for some seconds. Therefore, the borderline difference in $\tau$ between adults and children in this study may not hint to differences in the capacity of oxidative phosphorylation, but is more likely the result of a temporary inhibition of oxidative phosphorylation in adults, starting $\mathrm{PCr}$ recovery at lower $\mathrm{pH}$ values and very low oxygen levels.

In summary, during high-intensity intermittent plantar flexion exercise, in children's muscles a higher proportion of the ATP demand for muscle contraction was covered by oxidative ATP formation compared with adult's muscles. In children this resulted in a lower $\mathrm{PCr}$ during the first exercise interval, which enables children to start subsequent exercise interval with significantly higher $\mathrm{PCr}$ concentrations. Also muscle acidification was lower in children than in adults during the high-intensity intermittent exercise. It can be speculated that in children's muscles oxygen supply by perfusion during high-intensity intermittent exercise better meets the demand of oxygen for the increased rate of oxidative phosphorylation.

\section{Conclusions}

The present study showed that muscle high energy-rich phosphate kinetics during and after a high-intensity intermittent exercise normalised on $25 \%$ of the 1RM, is different in children and adults. Children have a clear advantage concerning the adaptation from rest to exercise which was highlighted by a lower $\mathrm{PCr}$ depletion at the onset of exercise. The average higher levels of $\mathrm{PCr}$ in children indicate that their muscles were able to cover their energy demands for contraction mainly by oxidative metabolism whereas adult's muscles were likely more ischaemic and rely more on anaerobic energy sources (i.e., $\mathrm{PCr}$ and anaerobic glycolysis). This was also highlighted by the lower $\mathrm{pH}$ values observed in adults. In children, energy metabolism seems to be no limiting factor during high-intensity interval exercise, which also explains the commonly known faster recovery of children from exhaustive exercise compared to adults. 


\section{References}

Armon Y, Cooper D, Flores R, Zanconato S, Barstow TJ (1991) Oxygen uptake dynamics during high-intensity exercise in children and adults. J Appl Physiol 70:841-848

Armstrong N, Fawkner SG (2008) Non-invasive methods in paediatric exercise physiology. Appl Physiol Nutr Metab 33:402-410

Arnold D, Matthews P, Radda G (1984) Metabolic recovery after exercise and the assessment of mitochondrial function in vivo in human skeletal muscle by means of ${ }^{31} \mathrm{P}$ NMR. Magn Reson Med $1: 307-315$

Bailey RC, Olson J, Pepper SL, Porszasz J, Barstow TJ, Cooper D (1995) The level and tempo of children's physical activities: an observational study. Med Sci Sport Exerc 27:1033-1041

Barker AR, Armstrong N (2010) Insights into developmental muscle metabolism through the use of ${ }^{31} \mathrm{P}$-magnetic resonance spectroscopy: a review. Pediatr Exerc Sci 22:350-368

Barker AR, Welsman JR, Welford D, Fulford J, Williams C, Armstrong N (2006) Reliability of ${ }^{31} \mathrm{P}$-magnetic resonance spectroscopy during an exhaustive incremental exercise test in children. Eur J Appl Physiol 98:556-565

Barker AR, Welsman JR, Fulford J, Welford D, Armstrong N (2008a) Muscle phosphocreatine kinetics in children and adults at the onset and offset of moderate-intensity exercise. J Appl Physiol 105:446-456

Barker AR, Welsman JR, Fulford J, Welford D, Williams CA, Armstrong N (2008b) Muscle phosphocreatine and pulmonary oxygen uptake kinetics in children at the onset and offset of moderate intensity exercise. Eur J Appl Physiol 102:727-738

Bar-Or O (1987) The Wingate anaerobic test: an update on methodology, reliability and validity. Sports Med 4:381-394

Barstow TJ, Buchthal S, Zanconato S, Cooper D (1994) Muscle energetics and pulmonary oxygen uptake kinetics during moderate exercise. J Appl Physiol 77:1742-1749

Bell R, MacDougall J, Billeter R, Howald H (1980) Muscle fiber types and morphometric analysis of skeletal muscle in six-yearold children. Med Sci Sports Exerc 12:28-31

Bendahan D, Confort-Gouny S, Kozak Reiss G, Cozzone PJ (1990) Heterogeneity of metabolic response to muscular exercise in humans. New criteria of invariance defined by in vivo phosphorus-31 NMR spectroscopy. FEBS Lett 272:155-158

Bendahan D, Mattei JP, Ghattas B, Confort-Gouny S, Le Guern ME, Cozzone PJ (2002) Citrulline/malate promotes aerobic energy production in human exercising muscle. $\mathrm{Br} \mathrm{J}$ Sports Med 36:282-289

Berg A, Kim S, Keul J (1986) Skeletal muscle enzyme activities in healthy young subjects. Int J Sports Med 7:236-239. doi:10. 1055/s-2008-1025766

Blei ML, Conley KE, Kushmerick MJ (1993) Separate measures of ATP utilization and recovery in human skeletal muscle. J Physiol 465:203-222

Boisseau N, Delamarche P (2000) Metabolic and hormonal responses to exercise in children and adolescents. Sports Med 30:405-422

Chia M, Armstrong N, Childs D (1997) The assessment of children's anaerobic performance using modifications of the Wingate anaerobic test. Pediatr Exerc Sci 9:80-89

Conley KE, Kemper WF, Crowther GJ (2001) Limits to sustainable muscle performance: interaction between glycolysis and oxidative phosphorylation. J Exp Biol 204:3189-3194

Cooper DM, Barstow TJ (1996) Magnetic resonance imaging and spectroscopy in studying exercise in children. Exerc Sports Sci Rev 24:475-500

Cooper DM, Berry C, Lamarra N, Wasserman K (1985) Kinetics of oxygen uptake and heart rate at onset of exercise in children. J Appl Physiol 59:211-217
Crowther GJ, Carey MF, Kemper WF, Conley KE (2002) Control of glycolysis in contracting skeletal muscle. I. Turning it on. Am J Physiol Endocrinol Metab 282:E67-E73

Doré E, Diallo O, Franca N, Bedu M, Van Praagh E (2000) Dimensional changes cannot account for all differences in shortterm cycling power during growth. Int J Sports Med 21:360-365

Dotan R, Bar-Or O (1983) Load optimization for the Wingate anaerobic test. Eur J Appl Physiol Occup Physiol 51:409-417

Dotan R, Ohana S, Bediz C, Falk B (2003) Blood lactate disappearance dynamics in boys and men following exercise of similar and dissimilar peak-lactate concentrations. J Pediatr Endocrinol Metab 16:419-429

Dotan R, Mitchell C, Cohen R, Klentrou P, Gabriel D, Falk B (2012) Child-adult differences in muscle activation-a review. Pediatr Exerc Sci 24:2-21

Eriksson BO (1980) Muscle metabolism in children-a review. Acta Paediatr 69:20-27

Eriksson BO, Gollnick PD, Saltin B (1973) Muscle metabolism and enzyme activities after training in boys 11-13 years old. Acta Physiol Scand 87:485-497

Eriksson BO, Gollnick PD, Saltin B (1974) The effect of physical training on muscle enzyme activities and fiber composition in 11-year-old boys. Acta Paediatr Belg 28(suppl):245-252

Evans WJ, Lexell J (1995) Human aging, muscle mass, and fiber type composition. J Gerontol A Biol Sci Med Sci 50(Special Issue): $11-16$

Falk B, Dotan R (2006) Child-adult differences in the recovery from high-intensity exercise. Exerc Sport Sci Rev 34:107-112

Fawkner SG, Armstrong N (2004) Longitudinal changes in the kinetic response to heavy-intensity exercise in children. J Appl Physiol 97:460-466. doi:10.1152/japplphysiol.00784.2003

Fawkner SG, Armstrong N, Potter CR, Welsman JR (2002) Oxygen uptake kinetics in children and adults after the onset of moderate-intensity exercise. J Sports Sci 20:319-326. doi:10. 1080/026404102753576099

Fleischman A, Makimura H, Stanley TL, McCarthy MA, Kron M, Sun N, Chuzi S, Hrovat MI, Systrom DM, Grinspoon SK (2010) Skeletal muscle phosphocreatine recovery after submaximal exercise in children and young and middle-aged adults. J Clin Endocrinol Metab 95:E69-E74

Forbes SC, Raymer G, Kowalchuk J, Thompson R, Marsh G (2008) Effects of recovery time on phosphocreatine kinetics during repeated bouts of heavy-intensity exercise. Eur J Appl Physiol 103:665-675

Gießing J (2003) Trainingsplanung und -steuerung beim Muskelaufbautraining. Das Konzept vom individuellen hypothetischen Maximalgewicht (h1RM) als methodische Alternative. Leistungssport 4/2003:26-31

Haralambie G (1982) Enzyme activities in skeletal muscle of 13-15 years old adolescents. Bull Eur Physiopathol Respir 18:65-74

Hebestreit H, Mimura K, Bar-Or O (1993) Recovery of muscle power after high-intensity short-term exercise: comparing boys and men. J Appl Physiol 74:2875-2880

Heck H, Mader A, Hess G, Mücke S, Müller R, Hollmann W (1985) Justification of the 4-mmol/l lactate threshold. Int J Sports Med 6:117-130. doi:10.1055/s-2008-1025824

Inbar O, Bar-Or O, Skinner JS (1996) The Wingate anaerobic test. Human Kinetics, Champaign

Kaczor JJ, Ziolkowski W, Popinigis J, Tarnopolsky MA (2005) Anaerobic and aerobic enzyme activities in human skeletal muscle from children and adults. Pediatr Res 57:331-335. doi:10.1203/01.PDR.0000150799.77094.DE

Kemp GJ, Radda GK (1994) Quantitative interpretation of bioenergetic data from ${ }^{31} \mathrm{P}$ and ${ }^{1} \mathrm{H}$ magnetic resonance spectroscopic 
studies of skeletal muscle: an analytical review. Magn Reson Q 10:43-63

Kemp GJ, Taylor DJ, Styles P, Radda GK (1993) The production, buffering and efflux of protons in human skeletal muscle during exercise and recovery. NMR Biomed 6:73-83

Kemp GJ, Taylor DJ, Thompson C, Hands L, Rajagopalan B, Styles $\mathrm{P}$, Radda GK (2005) Quantitative analysis by ${ }^{31} \mathrm{P}$ magnetic resonance spectroscopy of abnormal mitochondrial oxidation in skeletal muscle during recovery from exercise. NMR Biomed 6:302-310

Kuno S, Takahashi H, Fujimoto K, Akima H, Miyamura M, Nemoto I, Itai Y, Katsuta S (1995) Muscle metabolism during exercise using phosphorus-31 nuclear magnetic resonance spectroscopy in adolescents. Eur J Appl Physiol Occup Physiol 70:301-304

Larson-Meyer DE, Newcomer BR, Hunter GR, Joanisse DR, Weinsier RL, Bamman MM (2001) Relation between in vivo and in vitro measurements of skeletal muscle oxidative metabolism. Muscle Nerve 24:1665-1676

Layec G, Bringard A, Le Fur Y, Vilmen C, Micallef JP, Perrey S, Cozzone PJ, Bendahan D (2009) Reproducibility assessment of metabolic variables characterizing muscle energetics in vivo: a ${ }^{31}$ P-MRS study. Magn Reson Med 62:840-854. doi:10.1002/ mrm. 22085

Lexell J, Sjostrom M, Nordlund AS, Taylor CC (1992) Growth and development of human muscle: a quantitative morphological study of whole vastus lateralis from childhood to adult age. Muscle Nerve 15:404-409. doi:10.1002/mus.880150323

Lowenstein JM (1990) The purine nucleotide cycle revised. Int J Sports Med 11:37-46

Malina RM (1969) Quantification of fat, muscle and bone in man. Clin Orthop 65:9-38

Malina RM, Bouchard C, Bar-Or O (2004) Growth, maturation, and physical activity. Human Kinetics, Champaign

McCreary CR, Chilibeck PD, Marsh GD, Paterson DH, Cunningham DA, Thompson RT (1996) Kinetics of pulmonary oxygen uptake and muscle phosphates during moderate-intensity calf exercise. J Appl Physiol 81:1331-1338

Meyer RA (1988) A linear model of muscle respiration explains monoexponential phosphocreatine changes. Am J Physiol 254:C548-C553

Paraschos I, Hassani A, Bassa E, Hatzikotoulas K, Patikas D, Kotzamanidis C (2007) Fatigue differences between adults and prepubertal males. Int J Sports Med 28:958-963

Petersen S, Gaul C, Stanton M, Hanstock C (1999) Skeletal muscle metabolism during short-term, high-intensity exercise in prepubertal and pubertal girls. J Appl Physiol 87:2151-2156

Ratel S, Bedu M, Hennegrave A, Dore E, Duche P (2002a) Effects of age and recovery duration on peak power output during repeated cycling sprints. Int J Sports Med 23:397-402

Ratel S, Duche P, Hennegrave A, Van Praagh E, Bedu M (2002b) Acid-base balance during repeated cycling sprints in boys and men. J Appl Physiol 92:479-485

Ratel S, Duche P, Williams CA (2006) Muscle fatigue during highintensity exercise in children. Sports Med 36:1031-1065

Ratel S, Tonson A, Le Fur Y, Cozzone P, Bendahan D (2008) Comparative analysis of skeletal muscle oxidative capacity in children and adults: a ${ }^{31}$ P-MRS study. Appl Physiol Nutr Metab 33:720-727
Rico-Sanz J, Zehnder M, Buchli R, Kühne G, Boutellier U (1999) Noninvasive measurement of muscle high-energy phosphates and glycogen concentrations in elite soccer players by ${ }^{31} \mathrm{P}$-and ${ }^{13}$ C-MRS. Med Sci Sports Exerc 31:1580-1586

Robergs RA, Ghiasvand F, Parker D (2004) Biochemistry of exerciseinduced metabolic acidosis. Am J Physiol Regul Integr Comp Physiol 287:R502-R516

Rossiter H, Ward S, Kowalchuk J, Howe F, Griffiths J, Whipp B (2002) Dynamic asymmetry of phosphocreatine concentration and $\mathrm{O}_{2}$ uptake between the on-and off-transients of moderateand high-intensity exercise in humans. J Physiol 541:991-1002

Rothman DL, Shulman RG, Shulman GI (1992) ${ }^{31}$ P nuclear magnetic resonance measurements of muscle glucose-6-phosphate. Evidence for reduced insulin-dependent muscle glucose transport or phosphorylation activity in non-insulin-dependent diabetes mellitus. J Clin Invest 89:1069-1075

Roussel M, Bendahan D, Mattei J, Le Fur Y, Cozzone P (2000) ${ }^{31} \mathrm{P}$ Magnetic resonance spectroscopy study of phosphocreatine recovery kinetics in skeletal muscle: the issue of intersubject variability. Biochim Biophys Acta 1457:18-26

Taylor D, Bore PJ, Styles P, Gadian DG, Radda G (1983) Bioenergetics of intact human muscle. $\mathrm{A}{ }^{31} \mathrm{P}$ nuclear magnetic resonance study. Mol Biol Med 1:77-94

Taylor D, Kemp G, Thompson C, Radda G (1997) Ageing: effects on oxidative function of skeletal muscle in vivo. Mol Cell Biochem 174:321-324

Tonson A, Ratel S, Le Fur Y, Vilmen C, Cozzone PJ, Bendahan D (2010) Muscle energetics changes throughout maturation: a quantitative ${ }^{31} \mathrm{P}-\mathrm{MRS}$ analysis. J Appl Physiol 109:1769-1778

Tran TK, Sailasuta N, Kreutzer U, Hurd R, Chung Y, Mole P, Kuno S, Jue T (1999) Comparative analysis of NMR and NIRS measurements of intracellular $\mathrm{PO}_{2}$ in human muscle. Am $\mathrm{J}$ Physiol 276:R1682-R1690

Van Ekeren GJ, Cornelissen EA, Stadhouders AM, Sengers RC (1991) Increased volume density of peripheral mitochondria in skeletal muscle of children with exercise intolerance. Eur $\mathrm{J}$ Pediatr 150:744-750

Van Praagh E, Doré E (2002) Short-term muscle power during growth and maturation. Sports Med 32:701-728

Willcocks RJ, Williams CA, Barker AR, Fulford J, Armstrong N (2010) Age- and sex-related differences in muscle phosphocreatine and oxygenation kinetics during high-intensity exercise in adolescents and adults. NMR Biomed 23:569-577

Williams CA, Carter H, Jones AM, Doust JH (2001) Oxygen uptake kinetics during treadmill running in boys and men. J Appl Physiol 90:1700-1706

Zafeiridis A, Dalamitros A, Dipla K, Manou V, Galanis N, Kellis S (2005) Recovery during high-intensity intermittent anaerobic exercise in boys, teens, and men. Med Sci Sports Exerc 37: $505-512$

Zanconato S, Buchthal S, Barstow TJ, Cooper D (1993) ${ }^{31}$ P-magnetic resonance spectroscopy of leg muscle metabolism during exercise in children and adults. J Appl Physiol 74:2214-2218

Zange J, Beisteiner M, Müller K, Shushakov V, Maassen N (2008) Energy metabolism in intensively exercising calf muscle under a simulated orthostasis. Pflügers Arch Eur J Physiol 455: $1153-1163$ 